\title{
Induction of Apoptosis in Pancreatic Cancer Cells by CDDO-Me Involves Repression of Telomerase through Epigenetic Pathways
}

Dorrah Deeb ${ }^{1}$, Chris Brigolin ${ }^{2}$, Xiaohua Gao ${ }^{1}$, Yongbo Liu ${ }^{1}$, Kirit R. Pindolia ${ }^{2}$ and Subhash C. Gautam ${ }^{\text {* }}$

${ }^{1}$ Department of Surgery, Henry Ford Health System, Detroit, USA

${ }^{2}$ Department of Medical Genetics, Henry Ford Health System, Detroit, USA

*Corresponding author: Dr. Subhash C. Gautam, Ph.D, Surgical Research - 4D, Henry Ford Health System, One Ford Place, Detroit, MI 48202, USA, Tel: (313) 874-6998; Fax: (313) 874-3770; E-mail: sgautam1@hfhs.org

Received date: Mar 06, 2014, Accepted date: May 27, 2014, Pub date: May 31, 2014

Copyright: $\odot 2014$ Deeb D, et al. This is an open-access article distributed under the terms of the Creative Commons Attribution License, which permits unrestricted use, distribution, and reproduction in any medium, provided the original author and source are credited.

\begin{abstract}
Reactivation of telomerase in cancers provides an attractive target for developing novel agents to selectively destroy tumor cells. Methyl-2-cyano-3,12-dioxooleana-1,9(11)-dien-28-oate (CDDO-Me), a synthetic oleanane triterpenoid, inhibited cell proliferation and induced apoptosis in pancreatic cancer cells at very low concentrations. The antiproliferative and apoptosis-inducing effects of CDDO-Me were associated with the inhibition of human telomerase reverse transcriptase (hTERT) mRNA, hTERT protein and reduction in hTERT telomerase activity. CDDO-Me inhibited multiple transcription factors that regulate hTERT expression positively (Sp1, c-Myc and NF-KB) and negatively (CTCF, E2F-1 and MAD1). CDDO-Me inhibited protein levels of DNA methyl transferases DNMT1 and DNMT3a, which also resulted in hypomethylation of hTERT promoter. In addition, transcriptionally active chromatin markers, such as acetylated histone H3 (Lys 9), acetylated histone H4, di-methyl H3 (Lys 4) and tri-methyl H3 (Lys 9) were all reduced in pancreatic cancer cells treated with CDDO-Me. Chromatin immunoprecipitation analysis showed decreased histone deacetylation and histone demethylation at hTERT promoter. Collectively, these results indicate that down-regulation of telomerase through epigenetic mechanisms plays a critical role in induction of apoptosis in pancreatic cancer cells by CDDO-Me.
\end{abstract}

Keywords: CDDO-Me; Apoptosis; Telomerase; hTERT; Epigenetic control

\section{Introduction}

Pancreatic ductal adenocarcinoma (PDA) is the fourth leading cause of cancer-related deaths in the United States and is almost uniformly lethal with a 5 -year survival rate of $<5 \%$ [1-3]. Late initial diagnosis, aggressive metastatic behavior and resistance to chemoradiotherapy render pancreatic cancer one of the most difficult to treat malignant diseases. Surgical resection is curative; however, nearly $80 \%$ of the patients are diagnosed with locally advanced metastatic disease, precluding surgical intervention. Gemcitabine, the current standard of care for advanced pancreatic cancer, provides short-term symptomatic improvement with minor impact on survival and integration of multiple modalities has not improved survival $[4,5]$. Thus, there is a dire need to search for more active agents and novel strategies to treat pancreatic cancer.

Telomeres are nucleoprotein structures present at the end of chromosomes, which are essential in maintaining chromosome stability and integrity by preventing end-to-end fusion and chromosomal rearrangement [6]. During each cell division, telomere length is progressively shortened due to gradual loss of telomeric DNA repeat sequence (TTAGGG) [7,8]. The shortening of telomeres beyond a critical threshold leads to replicative senescence or apoptosis. Telomerase, a reverse transcriptase maintains the telomere length by adding the hexameric DNA repeats (TTAGGG) to the 3' flanking end of DNA strands in telomeres. The human telomerase complex consists of telomerase reverse transcriptase (hTERT), telomerase RNA template (TERC), telomerase associated protein-1 (TEP-1), hsp90 and p23 [9-11]. The telomerase activity in humans is highly regulated and is detectable only in germ line cells and some stem cells but is repressed in somatic cells $[12,13]$. Deregulated telomerase activity is associated with promotion of tumorigenesis and neoplastic growth of cancers $[7,14,15]$. In fact, approximately $90 \%$ of human cancers including pancreatic cancer exhibit reactivation of telomerase activity, contributing to the unlimited proliferation and replicative potential of cancer cells $[11,16]$. Thus, cancer-specific activation of telomerase provides an attractive target for selectively killing cancer cells with novel agents without damaging normal cells. Indeed, we have recently shown that inhibition of cell proliferation and induction of apoptosis in pancreatic cancer cells by methyl-2-cyano-3,12-dioxooleana-1, 9(11)-dien-28-oate (CDDO-Me), a synthetic oleanane triterpenoid, is associated with the repression of hTERT expression, the gene that codes for telomerase, and telomerase activity [17]. However in that study, experiments were performed using high concentrations of CDDO-Me and the mechanism of inhibition of hTERT expression was not adequately investigated. In the present study, we investigated the anti-proliferative and apoptosis-inducing activity of CDDO-Me in pancreatic cancer cells at very low concentrations and the effect they have on epigenetic regulatory processes involved in hTERT expression.

\section{Materials and Methods}

\section{Reagents}

CDDO-Me was obtained from the National Cancer Institute, Bethesda, MD through the Rapid Access to Intervention Development Program. A $100 \mathrm{mM}$ stock solution of CDDO-Me was prepared in 
DMSO, which was subsequently diluted in tissue culture medium to obtain the working concentrations. Antibodies against PARP-1, NF$\kappa B$ (p65), Sp1, c-Myc and $\beta$-actin were purchased from Santa Cruz Biotechnology, Inc. (Santa Cruz, CA). Anti-hTERT and p-TERT $\left(\mathrm{Ser}^{824}\right)$ antibodies were obtained from-Abcam Inc. (Cambridge, MA). Antibodies against DNMT1 and DNTM3a were from Cell Signaling (Danvers, MA). Anti-acetylated histone $\mathrm{H} 3$ at lysine 9 (ac-H3K9), anti- acetylated histone $\mathrm{H} 4$ (ac-H4), anti-histone dimethyl-H3 lysine 4 (di-me-H3K4) and anti-trimethy-H3 lysine 9 (ac-tri-me-H3K9) were purchased from Millipore (Temecula, CA). Annexin V-FITC apoptosis detection kit II was obtained from BD Pharmingen (San Diego, CA, USA) and TRAPeze telomerase detection kit was purchased from Millipore (Millipore, Temecula, CA).

\section{Cell lines}

Human pancreatic cancer cell lines MiaPaCa-2 and Panc-1 were obtained from the American Type Culture Collection (ATCC), Rockville, MD, USA. Both cell lines were cultured in DMEM tissue culture medium (Gibco BRL, Rockville, MD) supplemented with 10\% fetal bovine serum, 1\% penicillin/streptomycin, and $25 \mathrm{mM}$ HEPES buffer at $37^{\circ} \mathrm{C}$ in a humidified atmosphere consisting of $5 \% \mathrm{CO}_{2}$ and $95 \%$ air. Cells were maintained by splitting cultures twice a week.

\section{Measurement of cell viability}

$0.5 \times 10^{6}$ Panc- 1 or MiaPaCa- 2 pancreatic cancer cells in $10 \mathrm{~mL}$ tissue culture medium were added to $100 \mathrm{~mm}^{2}$ petri plates and allowed to adhere for $24 \mathrm{~h}$. Cells were then treated with CDDO-Me at concentrations ranging from 0 to $0.5 \mu \mathrm{M}$ for 5 days in triplicates. At the end of incubation period, cells were harvested by trypsinization and viability determined by trypan blue dye exclusion using a hemocytometer.

\section{Apoptosis assay}

Apoptosis was assessed by the binding of annexin V-FITC to phosphotidylserine, which is externalized to the outer leaflet of the plasma membrane early during induction of apoptosis. Briefly, untreated cells and cells treated with CDDO-Me were resuspended in the binding buffer provided in the annexin V-FITC apoptosis detection kit II (BD Biosciences, San Diego, CA, USA) and allowed to react with $5 \mu \mathrm{l}$ of annexin V-FITC reagent and $5 \mu \mathrm{l}$ of propidium iodide (PI) for $30 \mathrm{~min}$ at room temperature in the dark. Stained cells were analyzed by flow cytometry using Accuri C6 flow cytometer (Accuri Cytometers Inc. Ann Arbor, MI). The induction of apoptosis by CDDO-Me was confirmed from the cleavage of PARP-1 by western blotting.

\section{Measurement of hTERT expression}

The effect of CDDO-Me on hTERT expression was measured by analyzing hTERT mRNA and hTERT protein. For hTERT mRNA, total cellular RNA was extracted with TRI-zol reagent (GIBCO) according to the manufacturer's recommendation. $1 \mu \mathrm{g}$ of RNA was then reverse transcribed by oligo-dt primer and high fidelity reverse transcriptase (Boehringer Mannheim, Germany) to generate cDNAs. One $\mu \mathrm{L}$ of $\mathrm{cDNA}$ was used as the template for polymerase chain reaction (PCR) using hTERT primers: upper, 5'TGTTTCTGGATTTGCAGGTG-3', and lower, 5'GTTCTTGGCTTTCAGGATGG-3'; and GAPDH primers: upper, 5' TCCCTCAAG ATTGTCAGCAA-3', and lower, 5'-
AGATCCACAACGGATACATT-3'. The PCR conditions used were 33 cycles of denaturation $\left(95^{\circ} \mathrm{C}\right.$ for $\left.1 \mathrm{~min}\right)$, annealing $\left(62^{\circ} \mathrm{C}\right.$ for $\left.30 \mathrm{sec}\right)$ and polymerization $\left(72^{\circ} \mathrm{C}\right.$ for $\left.1 \mathrm{~min}\right)$. The PCR products were separated on $2 \%$ agarose gel electrophoresis and visualized by ethidium bromide staining. Gels were photographed and band densities were analyzed using the $\mathrm{NIH} / \mathrm{Scion}$ image analysis software. The hTERT primers amplified a DNA fragment of $200 \mathrm{bp}$ and the DNA fragment size amplified by GAPDH primers was $173 \mathrm{bp}$.

Total and phosphorylated hTERT protein levels were measured by western blotting as described below.

\section{Western blotting}

Cell lysates were prepared in lysis buffer containing 1\% Triton-X $100(\mathrm{v} / \mathrm{v}), 10 \mathrm{mM}$ Tris- $\mathrm{HCl}(\mathrm{pH} 7.5), 5 \mathrm{mM}$ EDTA, $150 \mathrm{mM} \mathrm{NaCl}$, $10 \%$ glycerol, $2 \mathrm{mM}$ sodium vanadate, $5 \mu \mathrm{g} / \mathrm{mL}$ leupeptin, $1 \mu \mathrm{g} / \mathrm{mL}$ aprotinin, $1 \mu \mathrm{g} / \mathrm{mL}$ pepstatinin, and $10 \mu \mathrm{g} / \mathrm{mL}$ 4-2-aminoethylbenzenesulfinyl fluoride). Lysates were clarified by centrifugation at $14,000 \mathrm{x} \mathrm{g}$ for $10 \mathrm{~min}$ at $4^{\circ} \mathrm{C}$, and protein concentrations were determined by Bradford assay. Samples $(50 \mu \mathrm{g})$ were boiled in an equal volume of sample buffer (20\% glycerol, $4 \%$ SDS, $0.2 \%$ Bromophenol Blue, $125 \mathrm{mM}$ Tris- $\mathrm{HCl}$ ( $\mathrm{pH} 7.5$ ), and $640 \mathrm{mM}$ 2-mercaptoethanol) and separated on pre-casted Tris-glycine polyacrylamide gels using the XCell SurelockTM Mini-Cell, in Tris-Glycine SDS running buffer, all from Novex (Invitrogen, Carlsbad, CA). Proteins resolved on the gels were transferred to nitrocellulose membranes. Membranes were blocked with $5 \%$ milk in $10 \mathrm{mM}$ Tris- $\mathrm{HCl}(\mathrm{pH} 8.0), 150 \mathrm{mM} \mathrm{NaCl}$ with $0.05 \%$ Tween 20 (TPBS) and probed using target specific antibodies or $\beta$-actin as loading control and HRP-conjugated secondary antibody. Immune complexes were visualized with enhanced chemiluminescence. Protein bands were imaged and band densities analyzed by $\mathrm{NIH} /$ Scion image analysis software. The protein band densities were normalized to the corresponding $\beta$-actin band densities.

\section{Telomerase activity assay}

The telomerase activity in cell extracts was assessed by the PCRbased telomeric repeat amplification protocol (TRAP) using TRAPeze gel-based telomerase detection kit (Millipore, Temecula, CA). Briefly, cells were extracted in CHAP lysis buffer on ice for 30 minutes. Two $\mu \mathrm{L}(100 \mathrm{ng})$ of cell extract was added to the TRAP reaction mixture containing dNTPs, TS primer, TRAP primers and Taq polymerase and incubated at $30^{\circ} \mathrm{C}$ for 30 minutes in a thermocycler followed by 3-step PCR at $94^{\circ} \mathrm{C} / 30 \mathrm{sec}, 59^{\circ} \mathrm{C} / 30 \mathrm{sec}$, and $72^{\circ} \mathrm{C} / 1$ minute for 33 cycles. The PCR products were fractionated on nondenaturing $12.5 \%$ polyacrilamide gel and visualized by staining with ethidium bromide. The ladder of products with 6 base pair increment indicating telomerase activity was analyzed with $\mathrm{NIH} /$ Scion image analysis software. The cumulative band density for each lane was normalized to the corresponding band density of internal control (36 bp).

\section{Chomatin immunoprecipitaion (ChIP) assay}

ChIP analysis of transcriptionally active chromatin markers interacting with hTERT promoter was performed using the EZ-ChIP kit (Upstate Biotechnology) according to the instructions included in the kit. ChIP-validated antibodies used were: anti-acetyl-histone $\mathrm{H} 3$ lysine 9, anti-acetyl-histone $\mathrm{H} 4$, anti-tri-methyl histone $\mathrm{H} 3$ lysine 9 and anti-di-methyl histone $\mathrm{H} 3$ lysine 4, all from Millipore. ChIPpurified DNA from control cells (untreated) and cells treated with 
Citation: Deeb D, Brigolin C, Gao X, Liu Y, Pindolia KR, et al. (2014) Induction of Apoptosis in Pancreatic Cancer Cells by CDDO-Me Involves

CDDO-Me $(0.125-0.5 \mu \mathrm{M})$ for 5 days was amplified by PCR using hTERT promoter primers: forward, 5'TCCCCTTCACGTCCGGCATT-3'; $\quad$ r'; AGCGGAGAGAGGTCGAATCG-3'. The PCR products were separated on $2 \%$ agarose gel electrophoresis and visualized by ethidium bromide staining. The hTERT primers amplified a DNA fragment of $200 \mathrm{bp}$.

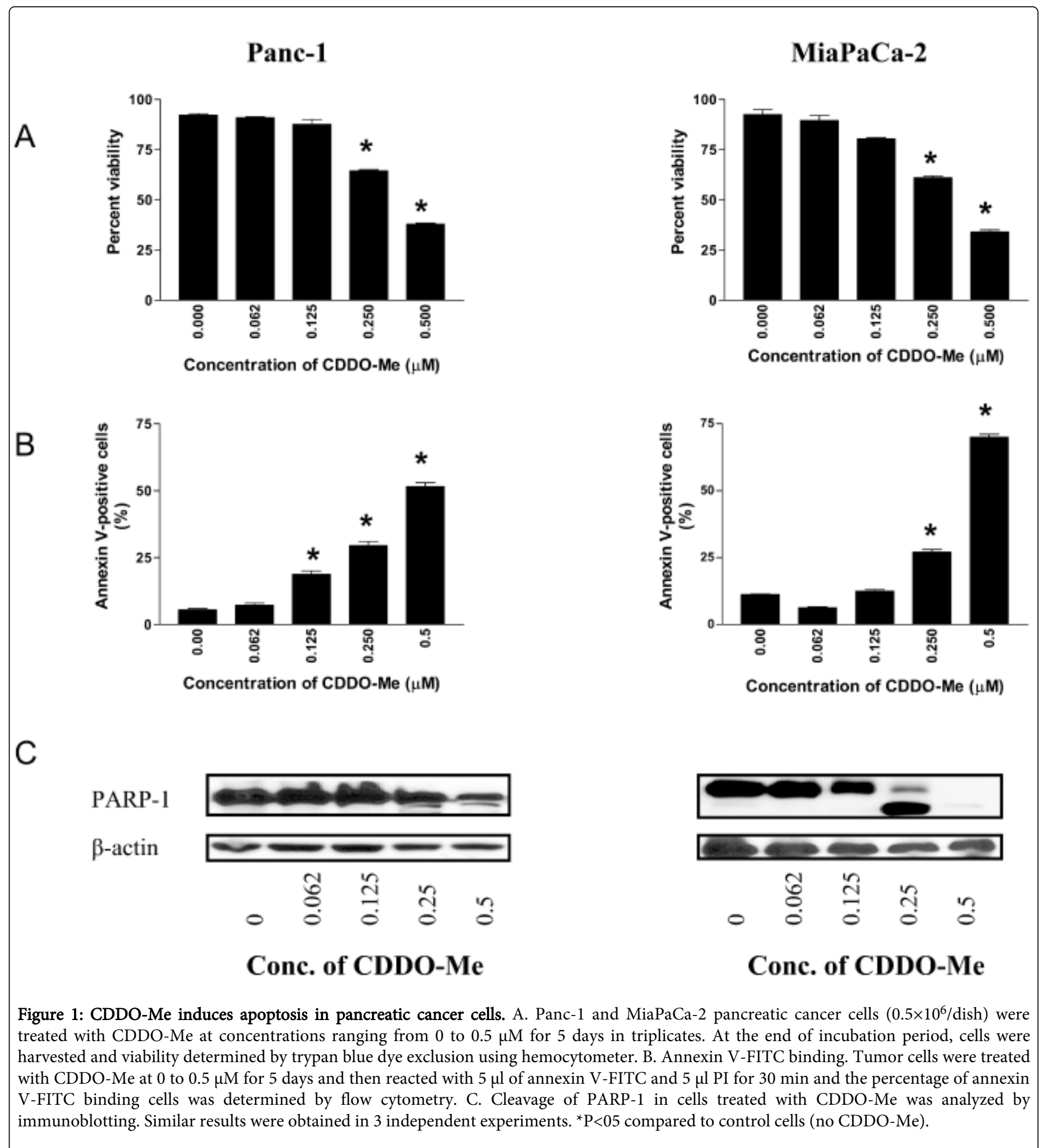


Citation: Deeb D, Brigolin C, Gao X, Liu Y, Pindolia KR, et al. (2014) Induction of Apoptosis in Pancreatic Cancer Cells by CDDO-Me Involves Repression of Telomerase through Epigenetic Pathways. J Carcinog \& Mutagen 5: 177. doi:10.4172/2157-2518.1000177

Page 4 of 11

\section{Bisulfite sequencing analysis}

Genomic DNA from Panc-1 cells treated or not with CDDO-Me for 5 days was isolated using Blood and Cell Culture DNA mini kit (Qiagen, Valencia, CA). $2 \mu \mathrm{g}$ of DNA was used in an overnight bisulfite reaction using the Epitect Bisulfite Conversion kit (Qiagen, Valencia, CA) according to the instruction provided with the kit.

Following the genome wide conversion of unmethylated Cs to Ts, 0.1-0.2 $\mu \mathrm{g}$ of DNA from each sample was used in a $20 \mu \mathrm{l}$ PCR reaction carried out at $95^{\circ} \mathrm{C}$ for 5 minutes for initial denaturation followed by 40 cycles of $\left[95^{\circ} \mathrm{C}\right.$ for 30 seconds, $62^{\circ} \mathrm{C}$ for 45 seconds, and $72^{\circ} \mathrm{C}$ for 60 seconds], and final extension step of $72^{\circ} \mathrm{C}$ for 10 minutes. The bisulfite specific primers were designed using Methyl Primer Express software from ABI (LifeTechnology, Grand Island, NY). The primers were designed to non-discriminately amplify hTERT promoter region spanning -248 to +108 . The forward primer sequence was 5'GTTTTTTAYGTGGYGGAG-3' and the reverse primer sequence was 5'-CCACCCTAAAACCCCAA-3'. PCR products were fractionated on $1.7 \%$ agarose gel and 356bp PCR fragments were cut out from the agarose gel and purified using QIAQuick Gel Extraction kit (Qiagen Valencia, CA). The purified PCR products were cloned using TA cloning kit (LifeTechnology, Grand Island, NY). Positive clones confirmed by restriction digestion were sequenced (Sequencing Core, University of Michigan, Ann Arbor, MI).

\section{Statistical analysis}

Most data are presented as means $\pm S$.D. Outcomes for treated and untreated cells were compared by Student's t-test. Differences were considered significant at $\mathrm{p}<0.05$.

\section{Results}

\section{CDDO-Me inhibits proliferation and induce apoptosis in pancreatic cancer cells}

To measure the effect of low concentrations of CDDO-Me on proliferation, Panc-1 and MiaPaCa-2 cells were treated with CDDO$\mathrm{Me}$ at concentrations ranging from 0.125 to $0.5 \mu \mathrm{M}$ for five days. At the end of the treatment, viability of cultures was determined by counting cells stained with trypan blue using a hemocytometer. As shown in Figure 1A, CDDO-Me significantly reduced the proliferation of both cell lines (measured from the loss of viability of cultures) at concentrations of $0.125 \mu \mathrm{M}$ to $0.5 \mu \mathrm{M}(\mathrm{p}<0.05)$.

To determine whether CDDO-Me induces apoptosis in pancreatic cancer cells, we first measured the binding of annexin V-FITC to Panc-1 and MiaPaCa-2 cells treated with CDDO-Me by flow cytometry. Since cells in early-stage apoptosis are stained by annexin V-FITC only and those in advanced stages of apoptosis are stained both by annexin V-FITC and PI, data presented in Figure 1B are average of cells stained by annexin V-FITC only plus cells dually stained by annexin V-FITC and PI (see supplementary Figure S1). Treatment with CDDO-Me $(0.125$ to $0.5 \mu \mathrm{M})$ significantly increased the percentage of annexin V-FITC plus annexin V-FITC/PI binding cells in both cell lines [Panc-1 cell, $19 \%$ to $52 \%$ at 0.125 to $0.5 \mu \mathrm{M}$ CDDO-Me $(\mathrm{p}<0.05)$; MiaPaCa-2 cells, $13 \%$ to $69 \%$ at 0.125 to $0.5 \mu \mathrm{M}$ CDDO-Me $(\mathrm{p}<0.05)]$.
The induction of apoptosis by CDDO-ME was confirmed by the cleavage of PARP-1 by western blotting. As shown in Figure 1C, native PARP-1 $(110 \mathrm{kDa})$ was clearly cleaved in MiaPaCa-2 cells at CDDOMe concentrations of 0.125 to $0.5 \mu \mathrm{M}$ as identified by reduction in total PARP-1 levels and by the appearance of a cleaved PARP-1 fragment $(89 \mathrm{kDa})$. Although native PARP-1 was also reduced in Panc- 1 cells at $0.25-0.5 \mu \mathrm{M}$ CDDO-Me, but the cleaved PARP-1 fragment was only weakly detectable.

\section{CDDO-Me inhibits expression of hTERT gene in pancreatic cancer cells}

The inhibition of telomerase leads to cellular senescence and/or apoptosis $[18,19]$. Thus, we determined the effect of CDDO-Me on the expression hTERT and hTERT telomerase activity. The effect of CDDO-Me on hTERT expression was measured by analyzing hTERT mRNA and hTERT protein expression. Analysis of hTERT mRNA by RT-PCR showed more than 50\% inhibition of hTERT mRNA in both cell lines after treatment with CDDO-Me at $0.125 \mu \mathrm{M}$ for 5 days. Complete inhibition of hTERT mRNA was observed at $0.25-0.5 \mu \mathrm{M}$ CDDO-Me without significantly affecting the expression of GAPDH in Panc-1 cells, but GAPDH mRNA in MiaPaCa-2 cells was partially reduced at 25-0.50 $\mu \mathrm{M}$ CDDO-Me (Figure 2A). CDDO-Me also inhibited the levels of native hTERT protein at 0.062-0.5 $\mu \mathrm{M}$ in both cell lines (Figure 2B). Since phosphorylation of the catalytic subunit of hTERT is necessary for its telomerase activity, we also measured the effect of CDDO-Me on phosphorylated hTERT. As shown in Figure 2B, CDDO-Me also inhibited p-hTERT at concentrations of 0.25-0.5 $\mu \mathrm{M}$ (Figure 2B).

Whether inhibition of hTERT expression by CDDO-Me results in decrease in telomerase activity was investigated next. After treatment with CDDO-Me (0.062 to $0.5 \mu \mathrm{M})$ for 5 days, Panc- 1 and MiaPaCa-2 cells were extracted in CHAP lysis buffer and the telomerase activity in extracts was measured by the PCR-based TRAP assay. Treatment with CDDO-Me drastically reduced the telomerase activity in a dosedependent manner, resulting in $90 \%-100 \%$ reduction in telomerase activity in both cell lines (Figure S2).

Collectively, attenuation of hTERT mRNA, basal and phosphohTERT protein and telomerase activity by CDDO-Me indicated that telomerase is a potential target of CDDO-Me in pancreatic cancer cells.

\section{CDDO-Me inhibits transcription factors that regulate hTERT expression}

The transcription of hTERT gene is regulated by a number of transcription factors. The hTERT core promoter contains transcription factor binding sites for Sp1, c-Myc, NF- $\mathrm{BB}$ and STAT-3 [20-22] that up-regulate hTERT expression. Therefore, we assessed the effect of CDDO-Me on the levels of these proteins. Treatment with CDDO-Me $(0$ to $0.5 \mu \mathrm{M})$ for 5 days partially to completely reduced the levels of Sp1, c-Myc and NF- $\mathrm{BB}$ (p65) at 0.125 to $0.5 \mu \mathrm{M}$ CDDO-Me (Figure $3 \mathrm{~A}$ ), suggesting that inhibition of these transcription factors likely contributes to the inhibition of hTERT transcription by CDDOMe. 
Citation: Deeb D, Brigolin C, Gao X, Liu Y, Pindolia KR, et al. (2014) Induction of Apoptosis in Pancreatic Cancer Cells by CDDO-Me Involves

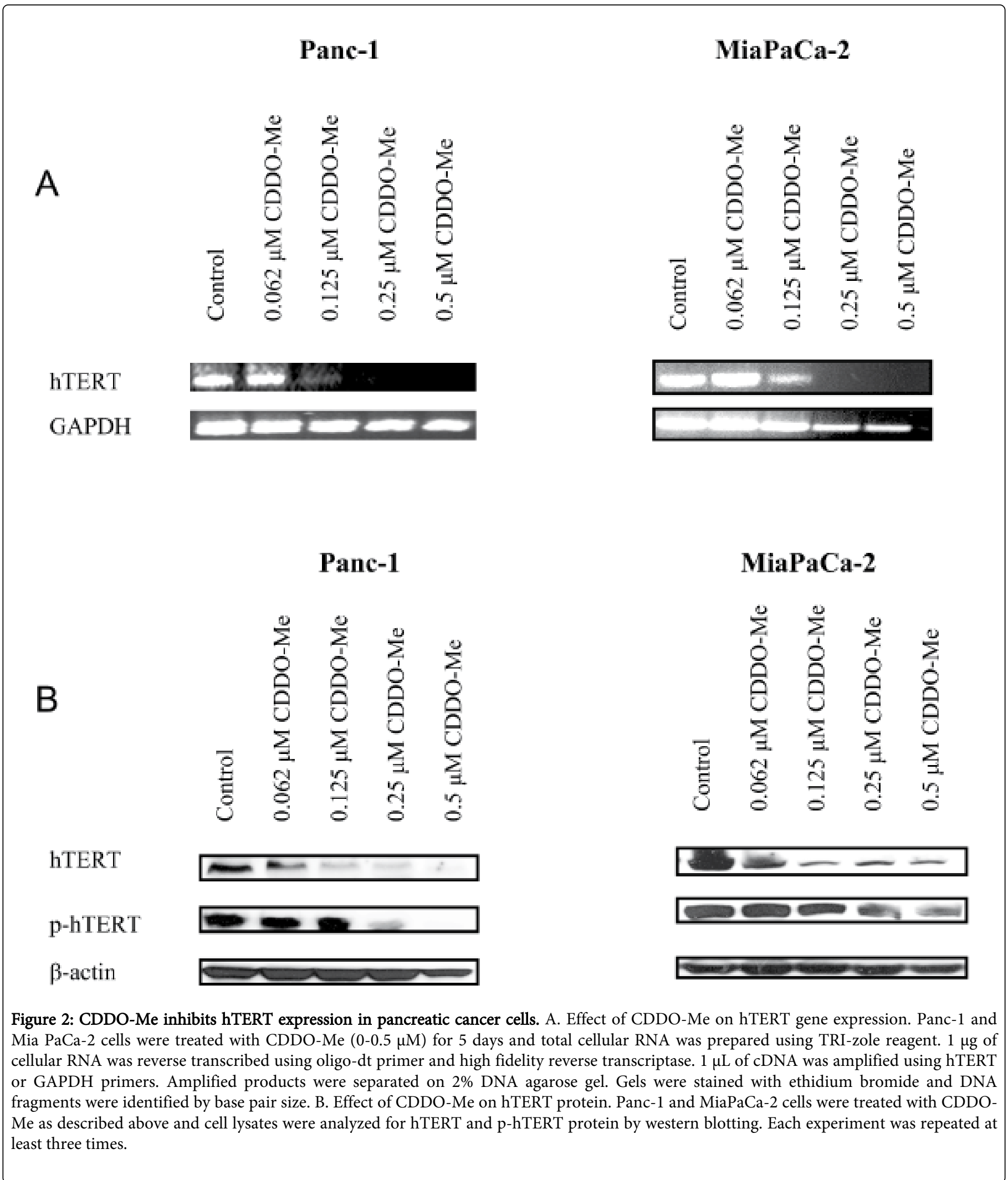


Citation: Deeb D, Brigolin C, Gao X, Liu Y, Pindolia KR, et al. (2014) Induction of Apoptosis in Pancreatic Cancer Cells by CDDO-Me Involves

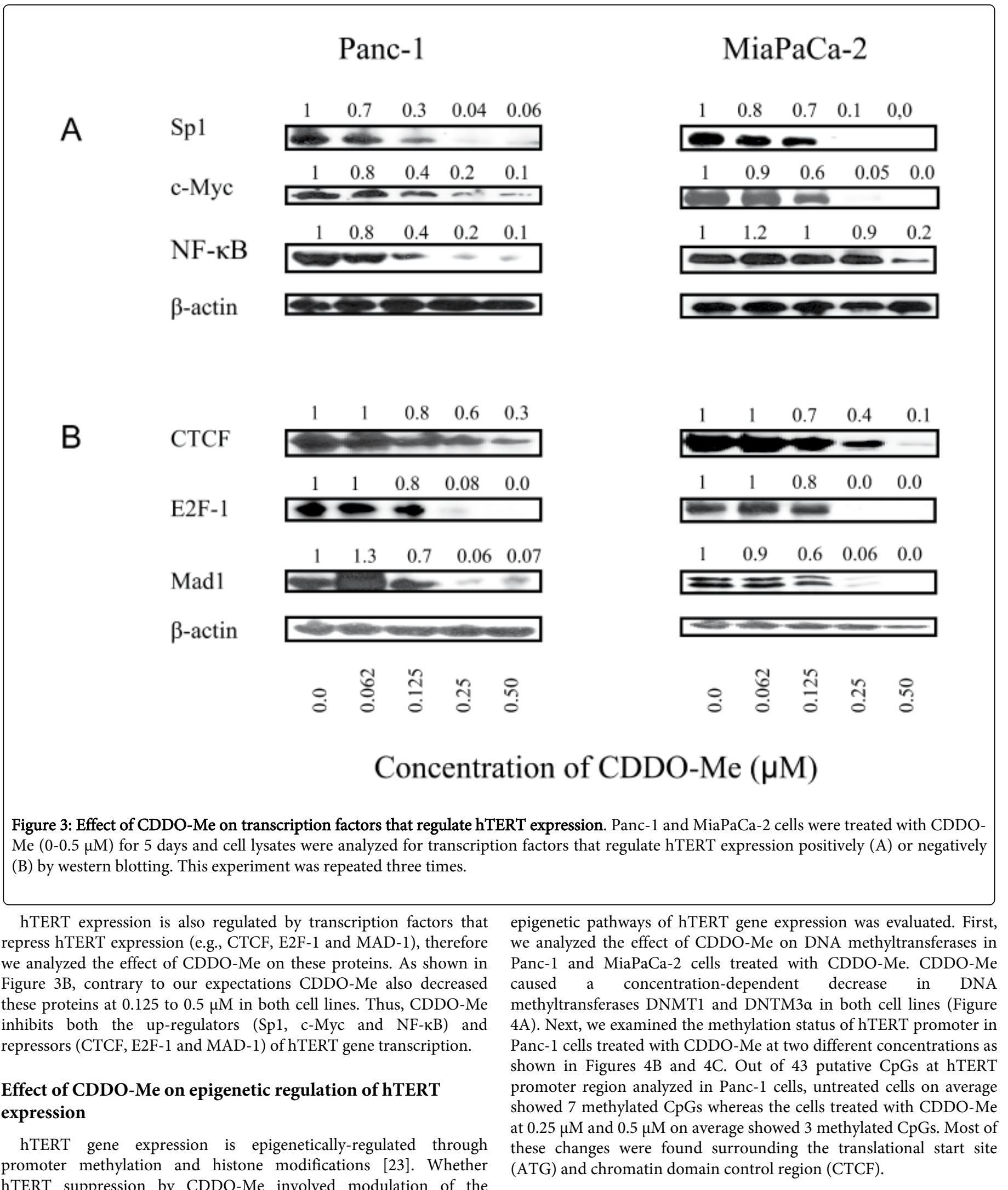


Citation: Deeb D, Brigolin C, Gao X, Liu Y, Pindolia KR, et al. (2014) Induction of Apoptosis in Pancreatic Cancer Cells by CDDO-Me Involves

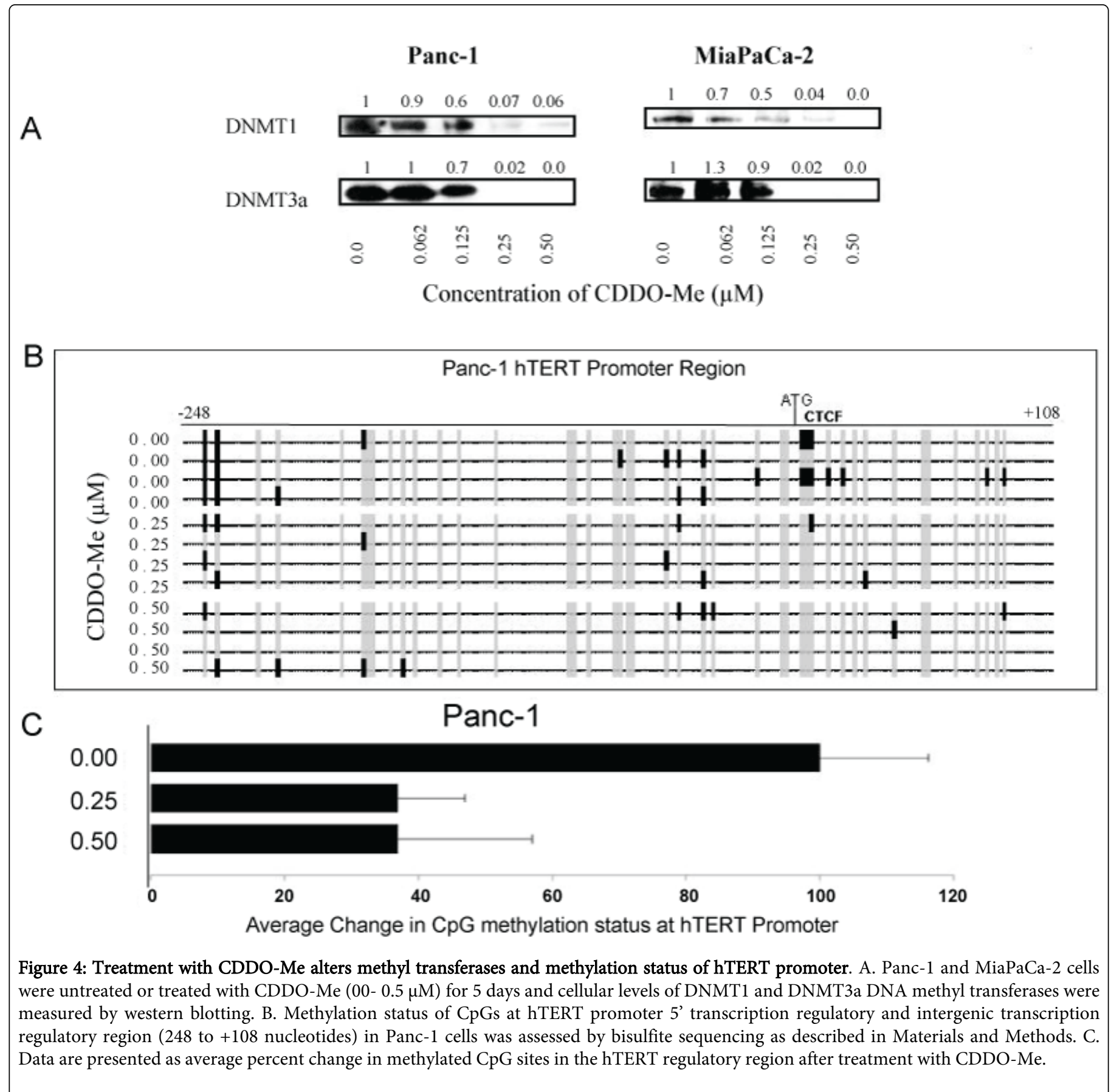

In addition to DNA methylation, histone acetylation and histone methylation play pivotal roles in hTERT expression. Whether treatment with CDDO-Me affects histone modifications was investigated next. For this, we first examined the effect of CDDO-Me on cellular levels of transcriptionally active acetylated histone $\mathrm{H} 3$ at lysine 9 (ac-H3K9) and acetylated histone $\mathrm{H} 4$ (ac-H4, Figure 5A).
Treatment with CDDO-Me dose-dependently reduced the levels of ac$\mathrm{H} 3 \mathrm{~K} 9$ and ac-H4 in both cell lines (Figure 5A). Similarly, levels of histone markers dimethyl-H3 lysine 4 (di-me-H3K4) and trimethy-H3 lysine 9 (ac-tri-me-H3K9) were also reduced in cells treated with CDDO-Me (Figure 5A). 
Citation: Deeb D, Brigolin C, Gao X, Liu Y, Pindolia KR, et al. (2014) Induction of Apoptosis in Pancreatic Cancer Cells by CDDO-Me Involves

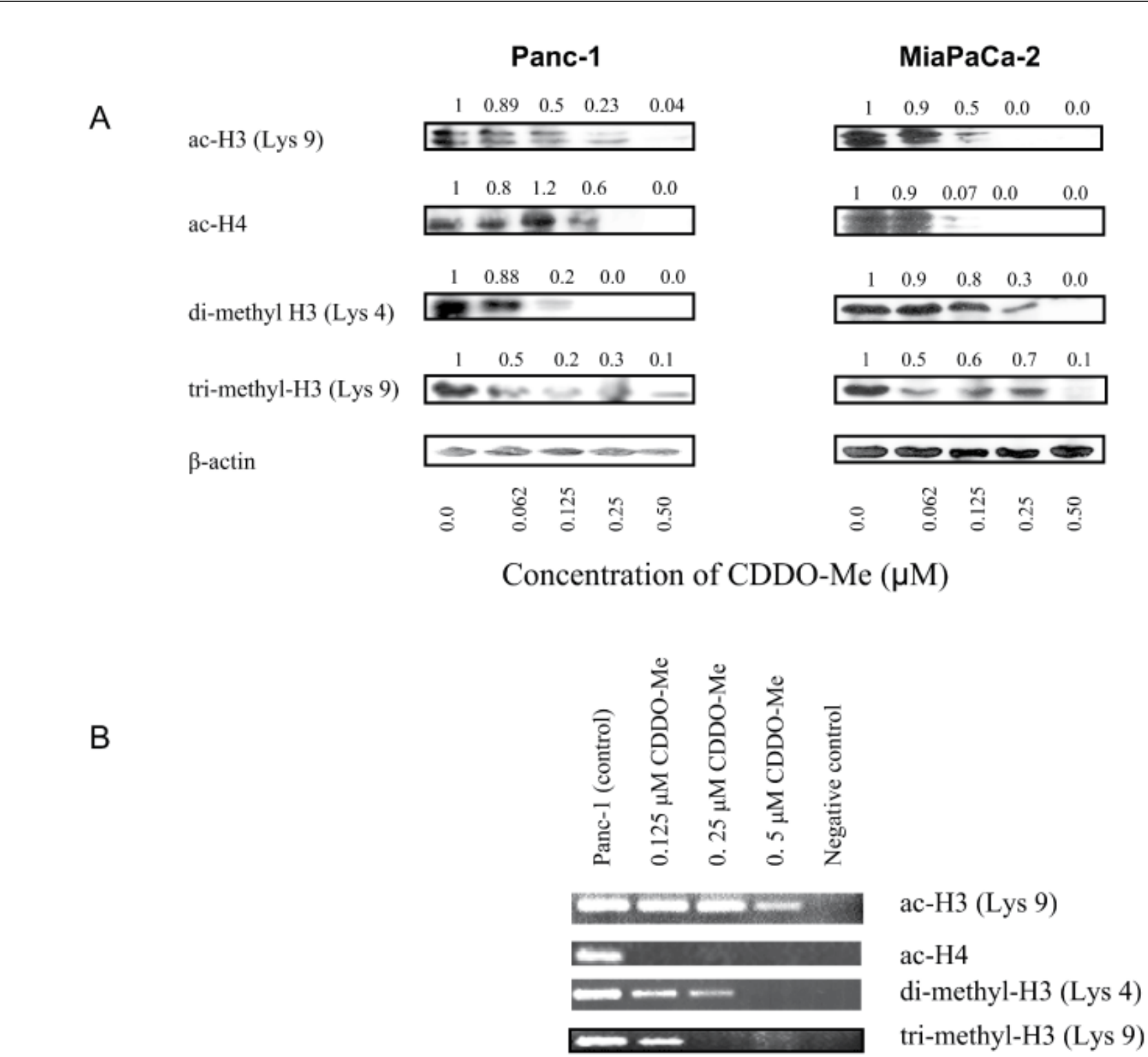

Figure 5: CDDO-Me induces chromatin modifications. A. Effect on transcriptionally active chromatin markers. Panc-1 and MiaPaCa-2 cells were treated with CDDO-Me $(0-0.5 \mu \mathrm{M})$ for 5 days and cell lysates were analyzed for acetylated histone $\mathrm{H} 3$ (Lys 9), acetylated histone $\mathrm{H} 4$, dimethyl $\mathrm{H} 3$ (Lys 4) and tri-methyl $\mathrm{H} 3$ (Lys 9) by western blotting. B. CDDO-Me induces changes in histone modification in regulatory region of hTERT promoter. Panca-1 cells were treated with CDDO-Me as described above and active chromatin markers interacting with hTERT promoter (acetylated histone H3 (Lys 9), acetylated histone H4, di-methyl H3 (Lys 4) and tri-methyl H3 (Lys 9) were analyzed by ChIP-PCR assay as described in Materials and Methods. No antibody controls were included to verify ChIP efficacy. The experiment was repeated two times.

Decrease in transcriptionally active histone markers described above suggested that attenuation of hTERT expression by CDDO-Me might result from changes in histone modification in the hTERT promoter. Thus, we analyzed changes in histone acetylation and histone methylation in the regulatory region of hTERT promoter by ChIP assay in Panc-1 cells treated with CDDO-Me. As shown in Figure 5B, acetylated histone $\mathrm{H} 3$ at lysine 9 was reduced in cells treated with $\mathrm{CDDO}-\mathrm{Me}$ at $0.5 \mu \mathrm{M}$, whereas acetylated histone $\mathrm{H} 4$ was completely inhibited even at the lowest concentration of $0.125 \mu \mathrm{M}$. Histone methylation histone markers dimethyl-H3 lysine 4 and
trimethy-H3 lysine 9 were also decreased in cells treated with CDDOMe at concentrations of 0.0625 to $0.5 \mu \mathrm{M}$. These data indicated that inhibition of hTERT expression by CDDO-Me involves inhibition of histone modifications in hTERT regulatory region.

\section{Discussion}

CDDO-Me is a multifunctional compound with potent antiinflammatory and anticarcinogenic activity [24]. CDDO-Me inhibits proliferation and induces apoptisis in diverse cancer cell types in cell 
culture [25-28] and inhibit the growth of tumor implants and prevent development of cancers in mouse models [29-31]. The anticarcinogenic mechanisms of CDDO-Me involves inhibiting a number of prosurvival signaling pathways, such as MAPK (Erk1/2), $\mathrm{NF}-\mathrm{kB}$, and Akt/mTOR signaling [32-34]. hTERT expression and telomerase activity is elevated in vast majority of cancers including pancreatic cancers [11,16,35-37]. Reexpression of telomerase provides unlimited proliferative advantage to cancer cells and telomerase inhibition inhibits cell proliferation, inducing cellular senescence or apoptosis. Little is known about the interplay between the anticancer mechanisms of CDDO-Me and telomerase. In a previous study we have shown that inhibition of cell proliferation and induction of apoptosis in pancreatic cancer cells by CDDO-Me is associated with the inhibition of hTERT gene that codes for the catalytic subunit of telomerase and its telomerase activity; however, the molecular mechanism of hTERT inhibition by CDDO-Me was not elucidated. The results of the present study confirm our previous findings that induction of apoptosis even at very low concentrations of CDDO-Me used in this study is associated with the inhibition of hTERT expression and its telomerase activity. CDDO-Me could repress hTERT by inhibiting hTERT gene transcription and/or hTERT protein production. Our data showed inhibition of both hTERT gene expression and protein production. Further, it also inhibited the phosphorylation of hTERT protein. The attenuation of hTERT mRNA, basal hTERT and phospho-hTERT suggested that CDDO-Me might also inhibit telomerase activity. Indeed, our data demonstrated that treatment with CDDO-Me reduced the telomerase activity in both pancreatic cancer cell lines (Figure S2). Although reduction in cellular telomerase activity can be attributed to the inhibition of hTERT gene expression and/or inhibition of phosphorylation of hTERT, these data do not demonstrate whether CDDO-Me is able to directly inhibit the telomerase activity of hTERT. Overall, attenuation of hTERT gene expression, hTERT protein production and phosphorylation and telomerase activity indicated that inhibition of telomerase is part of the mechanism by which CDDO-Me inhibits proliferation and induce apoptosis in pancreatic cancer cells. These findings are in agreement with other reports showing that inhibition of hTERT telomerase activity is necessary for the antiproliferative and apoptosis-inducing activity of natural compounds including genistein, sulforaphane and green tea polyphenols [38-40]. However, more work is required to determine whether CDDO-Me directly binds and degrades RNA template of telomerase and if it also causes shortening of telomeres.

A number of factors and molecules that regulate hTERT transcription have been identified. The hTERT core promoter contains binding sites for several transcription factors such as Sp1, c-Myc and NF- $\kappa \mathrm{B}$ and STAT-3 [20-22]. Inhibition of these transcription factors would likely impact transcription of hTERT gene. Indeed, we found that CDDO-Me inhibited Sp1, c-Myc and NF- $\mathrm{BB}$ in Panc-1 and MiaPaCa-2 cells, indicating that diminished hTERT expression and protein production by CDDO-Me may be attributed to the inhibition of these transcription factors. Contrary to our expectations however, various repressors of gene transcription, such as CTCF, E2F-1 and MAD1 that negatively regulate hTERT expression were also reduced in cells treated with CDDO-Me. Since CDDO-Me inhibited transcription factors that both up-regulate and down-regulate hTERT gene expression, how is hTERT gene expression then inhibited? One possibility is that CDDO-Me exerts more inhibitory function on transcription factors that up-regulate hTERT expression (Sp1, c-Myc and NF- $\mathrm{kB}$ and STAT-3) than those that down-regulate its expression (e.g., CTCF, E2F-1 and MAD1). This conclusion however requires further elucidation.

As stated before, epigenetic mechanisms play critical roles in regulating hTERT expression. Contrary to the prevalent view that hypermethylation of gene promoters typically inhibits their transcription; hypermethylation of hTERT promoter is associated with increased hTERT expression [41,42]. Epigenetically, genes expression can be regulated through processes such as DNA methylation, chromatin remodeling and modulation of the activity of enzymes and factors associated with these processes. Studies have shown that DNA methylation plays an important role in hTERT transcription and DNA methylation is primarily the function of DNMTs [43]. DNMT1, a maintenance methyltransferase, maintains hypermethylation of hTERT promoter, whereas DNMT3a and DNMT3b are responsible for de novo activity. Treatment with CDDO-Me inhibited DNMT1 and DNMT3a in Panc-1 and MiaPaCa-2 cells. As expected, the inhibition of DNMT1 resulted in demethylation of hTERT promoter. The number of methylated CpGs in hTERT promoter was significantly reduced following treatment with CDDO-Me. These data correlated with the inhibition of hTERT expression and suggest that promoter demethylation plays an important role in inhibition of hTERT expression by CDDO-Me. Demethylation of hTERT promoter allows binding of repressors, such as CTCF or E2F-1 and silencing of hTERT expression $[39,40]$. CDDO-Me not only caused demethylation of hTERT promoter but also suppressed CTCF, E2F-1 and MAD-1. Thus, the exact mechanism by which demethylation of hTERT promoter leads to the inhibition of hTERT expression by CDDO-Me remains elusive.

Besides DNA methylation, histone acetylation and methylation also play critical roles in hTERT expression [44]. Histone modifications result in loosening of the chromatin, allowing binding of the activators and/or repressors of gene transcription at the gene promoters. We found decrease in cellular levels of transcriptionally active chromatin markers acetylated histones $\mathrm{H} 3$ and H4. CDDO-Me also affected the methylation of histone, since di-methyl-H3 lysine 4 and trimethylH3K9 were also reduced in cells treated with CDDO-Me. The alterations in chromatin markers were also found at the hTERT promoter. ChIP analysis showed decrease in ac- $\mathrm{H} 3$, ac- $\mathrm{H} 4$, dimethylH3 and tri-methy-H3K9 at hTERT promoter in cells treated with CDDO-Me. Together, these data demonstrate that inhibition of epigenetic processes such as DNA methylation and chromatin modifications plays a crucial role in inhibition of hTERT expression by CDDO-Me in pancreatic cancer cells. These findings corroborate the results of other studies in which other anticancer agents also inhibited hTERT expression in tumor cells by interfering with the epigenetic regulatory processes $[23,38-40]$.

\section{Conclusion}

The findings presented in this paper demonstrated that induction of apoptosis in pancreatic cancer cells by CDDO-Me is associated with the inhibition of hTERT and its telomerase activity. CDDO-Me inhibited hTERT mRNA and transcription factors that regulate hTERT gene expression positively and negatively (Spl, c-Myc, NF- $k B$, CTCF, E2F-1 and MAD-1). Among the epigenetic pathways of gene regulation, CDDO-Me inhibited, hTERT promoter methylation, DNA methytransferases and histone modifications (acetylation and methylation). Together, these data indicated that modulation of epigenetic processes plays a critical role in inhibition of telomerase in pancreatic cancer cells by CDDO-Me. 


\section{Financial Support}

This work was supported by NIH grant 1R01 CA130948-01 and a grant from Elsa U. Pardee Foundation.

\section{References}

1. Pancreatic Cancer-National Cancer Institute, U.S. National Institutes of Health. Cancer Gov.

2. Maitra A, Hruban RH (2008) Pancreatic cancer. Annu Rev Pathol 3: 157-188.

3. Li D1, Xie K, Wolff R, Abbruzzese JL (2004) Pancreatic cancer. Lancet 363: 1049-1057.

4. Mulcahy MF, Wahl AO, Small W Jr (2005) The current status of combined radiotherapy and chemotherapy for locally advanced or resected pancreas cancer. J Natl Compr Canc Netw 3: 637-642.

5. Pino SM, Xiong HQ, McConkey D, Abbruzzese JL (2004) Novel therapies for pancreatic adenocarcinoma. Curr Oncol Rep 6: 199-206.

6. Holt SE, Wright WE, Shay JW (1996) Regulation of telomerase activity in immortal cell lines. Mol Cell Biol 16: 2932-2939.

7. Blasco MA, Hahn WC (2003) Evolving views of telomerase and cancer. Trends Cell Biol 13: 289-294.

8. Newbold RF (2002) The significance of telomerase activation and cellular immortalization in human cancer. Mutagenesis 17: 539-550.

9. Cech TR (2004) Beginning to understand the end of the chromosome. Cell 116: 273-279.

10. Janknecht R (2004) On the road to immortality: hTERT upregulation in cancer cells. FEBS Lett 564: 9-13.

11. Meyerson M, Counter CM, Eaton EN, Ellisen LW, Steiner P, et al. (1997) hEST2, the putative human telomerase catalytic subunit gene, is up regulated in tumor cells and during immortalization. Cell 90: 785-795.

12. Wright WE, Piatyszek MA, Rainey WE, Byrd W, Shay JW (1996) Telomerase activity in human germline and embryonic tissues and cells. Dev Genet 18: 173-179.

13. Yasumoto S, Kunimura C, Kikuchi K, Tahara H, Ohji H, et al. (1996) Telomerase activity in normal human epithelial cells. Oncogene 13: 433-439.

14. Newbold RF (2002) The significance of telomerase activation and cellular immortalization in human cancer. Mutagenesis 17: 539-550.

15. Cech TR (2004) Beginning to understand the end of the chromosome. Cell 116: 273-279.

16. Janknecht R (2004) On the road to immortality: hTERT upregulation in cancer cells. FEBS Lett 564: 9-13.

17. Deeb D, Gao X, Liu Y, Kim SH, Pindolia KR, et al. (2012) Inhibition of cell proliferation and induction of apoptosis by oleanane triterpenoid (CDDO-Me) in pancreatic cancer cells is associated with the suppression of hTERT gene expression and its telomerase activity. Biochem Biophys Res Commun 422: 561-567.

18. Zhang X, Mar V, Zhou W, Harrington L, Robinson MO (1999) Telomere shortening and apoptosis in telomerase-inhibited human tumor cells. Genes Dev 13: 2388-2399.

19. Naasani I, Oh-Hashi F, Oh-Hara T, Feng WY, Johnston J, et al. (2003) Blocking telomerase by dietary polyphenols is a major mechanism for limiting the growth of human cancer cells in vitro and in vivo. Cancer Res 63: 824-830.

20. Kyo S, Takakura M, Taira T, Kanaya T, Itoh H, et al. (2000) Sp1 cooperates with c-Myc to activate transcription of the human telomerase reverse transcriptase gene (hTERT). Nucleic Acids Res 28: 669-677.

21. Konnikova L, Simeone MC, Kruger MM, Kotecki M, Cochran BH (2005) Signal transducer and activator of transcription 3 (STAT3) regulates human telomerase reverse transcriptase (hTERT) expression in human cancer and primary cells. Cancer Res 65: 6516-6520.

22. Kimura A, Ohmichi M, Kawagoe J, Kyo S, Mabuchi S, et al. (2004) Induction of hTERT expression and phosphorylation by estrogen via Akt cascade in human ovarian cancer cell lines. Oncogene 23: 4505-4515.
23. Daniel M, Peek GW, Tollefsbol TO (2012) Regulation of the human catalytic subunit of telomerase (hTERT). Gene 498: 135-146.

24. Liby KT, Yore MM, Sporn MB (2007) Triterpenoids and rexinoids as multifunctional agents for the prevention and treatment of cancer. Nat Rev Cancer 7: 357-369.

25. Ito Y, Pandey P, Sporn MB, Datta R, Kharbanda S, et al. (2001) The novel triterpenoid CDDO induces apoptosis and differentiation of human osteosarcoma cells by a caspase- 8 dependent mechanism. Mol Pharmacol 59: 1094-1099.

26. Konopleva M, Tsao T, Estrov Z, Lee RM, Wang RY, et al. (2004) The synthetic triterpenoid 2-cyano-3,12-dioxooleana-1,9-dien-28-oic acid induces caspase-dependent and -independent apoptosis in acute myelogenous leukemia. Cancer Res 64: 7927-7935.

27. Gao X, Deeb D, Jiang H, Liu Y, Dulchavsky SA, et al. (2007) Synthetic triterpenoids inhibit growth and induce apoptosis in human glioblastoma and neuroblastoma cells through inhibition of prosurvival Akt, NFkappaB and Notch1 signaling. J Neurooncol 84: 147-157.

28. Deeb D, Gao X, Arbab AS, Barton K, Dulchavsky SA, et al. (2010) CDDO-Me: A Novel Synthetic Triterpenoid for the Treatment of Pancreatic Cancer. Cancers (Basel) 2: 1779-1793.

29. Ling X, Konopleva M, Zeng Z, Ruvolo V, Stephens LC, et al. (2007) The novel triterpenoid C-28 methyl ester of 2-cyano-3, 12-dioxoolen-1, 9dien-28-oic acid inhibits metastatic murine breast tumor growth through inactivation of STAT3 signaling. Cancer Res 67: 4210-4218.

30. Liby KT, Royce DB, Risingsong R, Williams CR, Maitra A, et al. (2010) Synthetic triterpenoids prolong survival in a transgenic mouse model of pancreatic cancer. Cancer Prev Res (Phila) 3: 1427-1434.

31. Deeb D, Gao X, Liu Y, Jiang D, Divine GW, et al. (2011) Synthetic triterpenoid CDDO prevents the progression and metastasis of prostate cancer in TRAMP mice by inhibiting survival signaling. Carcinogenesis 32: 757-764.

32. Konopleva M, Contractor R, Kurinna SM, Chen W, Andreeff M, et al. (2005) The novel triterpenoid CDDO-Me suppresses MAPK pathways and promotes p38 activation in acute myeloid leukemia cells. Leukemia 19: $1350-1354$

33. Ahmad R, Raina D, Meyer C, Kharbanda S, Kufe D (2006) Triterpenoid CDDO-Me blocks the NF-kappaB pathway by direct inhibition of IKKbeta on Cys-179. J Biol Chem 281: 35764-35769.

34. Deeb D, Gao X, Jiang H, Dulchavsky SA, Gautam SC (2009) Oleanane triterpenoid CDDO-Me inhibits growth and induces apoptosis in prostate cancer cells by independently targeting pro-survival Akt and mTOR. Prostate 69: 851-860.

35. Ohuchida K, Mizumoto K, Yamada D, Yamaguchi H, Konomi H, et al. (2006) Quantitative analysis of human telomerase reverse transcriptase in pancreatic cancer. Clin Cancer Res 12: 2066-2069.

36. Grochola LF, Greither T, Taubert HW, Möller P, Knippschild U, et al. (2008) Prognostic relevance of hTERT mRNA expression in ductal adenocarcinoma of the pancreas. Neoplasia 10: 973-976.

37. Hashimoto Y, Murakami Y, Uemura K, Hayashidani Y, Sudo T, et al. (2008) Detection of human telomerase reverse transcriptase (hTERT) expression in tissue and pancreatic juice from pancreatic cancer. Surgery 143: 113-125.

38. Li Y, Liu L, Andrews LG, Tollefsbol TO (2009) Genistein depletes telomerase activity through cross-talk between genetic and epigenetic mechanisms. Int J Cancer 125: 286-296.

39. Meeran SM, Patel SN, Tollefsbol TO (2010) Sulforaphane causes epigenetic repression of hTERT expression in human breast cancer cell lines. PLoS One 5: e11457.

40. Meeran SM, Patel SN, Chan TH, Tollefsbol TO (2011) A novel prodrug of epigallocatechin-3-gallate: differential epigenetic hTERT repression in human breast cancer cells. Cancer Prev Res (Phila) 4: 1243-1254.

41. Renaud S, Loukinov D, Abdullaev Z, Guilleret I, Bosman FT, et al. (2007) Dual role of DNA methylation inside and outside of CTCF-binding regions in the transcriptional regulation of the telomerase hTERT gene. Nucleic Acids Res 35: 1245-1256. 
Citation: Deeb D, Brigolin C, Gao X, Liu Y, Pindolia KR, et al. (2014) Induction of Apoptosis in Pancreatic Cancer Cells by CDDO-Me Involves Repression of Telomerase through Epigenetic Pathways. J Carcinog \& Mutagen 5: 177. doi:10.4172/2157-2518.1000177

Page 11 of 11

42. Renaud S, Loukinov D, Bosman FT, Lobanenkov V, Benhattar J (2005) CTCF binds the proximal exonic region of hTERT and inhibits its transcription. Nucleic Acids Res 33: 6850-6860.

43. Bestor TH (2000) The DNA methyltransferases of mammals. Hum Mol Genet 9: 2395-2402.
44. Liu L, Lai S, Andrews LG, Tollefsbol TO (2004) Genetic and epigenetic modulation of telomerase activity in development and disease. Gene 340: $1-10$. 